\title{
Integration of Computational Toxicology, Toxicogenomics Data Mining, and Omics Techniques to Unveil Toxicity Pathways
}

\author{
Xiaoqing Wang, Fei Li,* Jingwen Chen, Chenglong Ji, and Huifeng $\mathrm{Wu}^{*}$
}

Cite This: ACS Sustainable Chem. Eng. 2021, 9, 4130-4138

Read Online

ABSTRACT: Growing numbers of synthetic chemicals have potential endocrine-disrupting effects and cause potential ecological and health risks. However, the primary toxicity pathways and mechanisms of endocrine disruption are poorly understood and the existing risk assessment relies heavily on animal testing. Database mining, omics technology, and computer simulation can serve as an alternative approach to explore the mechanisms by building adverse outcome pathways (AOPs). The present study took a case of thyroid interference with triphenyl phosphate (TPP) to explain the potential toxic effects at levels from submolecules to cells utilizing the AOP framework developed by multiple techniques. This study retrieved the data from a comparative toxicogenomics database (CTD) and screened out the core gene. Molecular dynamics (MD) analysis was used to explore configuration changes and confirm the molecular initiating event (MIE).

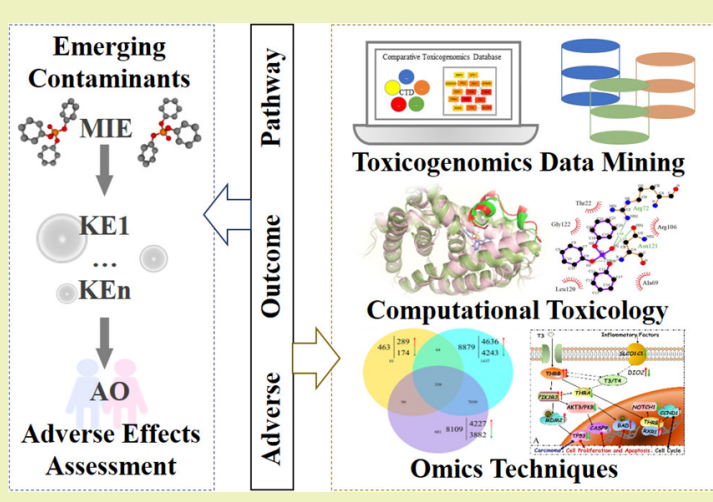
The transcriptomic analysis was further utilized to supplement the relationships between MIEs and key events (KEs) of the AOP. The thyroid hormone receptor beta (THRB) was identified as the core gene at submolecular levels. MD analysis found that the configuration changes of C-terminal helix 12 (H12) of thyroid hormone receptor $\beta(\operatorname{TR} \beta)$ were discovered as the MIE. The transcriptomic analysis extended the related KE1 at the subcellular level, such as changes in gene expression levels for coding cycle regulation (CCND1), inflammatory response (IL1A and IL6), and cell proliferation and apoptosis (BAD, TP53, and CASP9). Then, the KE2 at cellular levels such as apoptosis, cell cycle control, and cell proliferation were influenced accordingly. As a result, these alterations led to thyroid disorder as adverse outcomes. This study provided an efficient way to facilitate the complement of possible AOPs and brought new insights into understanding the toxic mechanisms of emerging synthetic chemicals.

KEYWORDS: Adverse outcome pathway (AOP), Comparative toxicogenomics database (CTD), Triphenyl phosphate (TPP), Molecular dynamics (MD), Transcriptome analyses

\section{INTRODUCTION}

More than 350000 chemicals and their mixtures have been registered for commercial production and used in a global inventory, up to three times as many as scientists commonly estimate. ${ }^{1}$ It is unfeasible to make extensive use of animal tests to determine whether an emerging compound may or may not exert endocrine-disrupting actions of thousands of chemicals that lack toxicology data. ${ }^{2}$ Hence, more rapid and effective methods are increasingly needed to fully elucidate the potential toxicity of emerging pollutants.

The strategy for toxicity pathway analysis is significant to fulfill the needs of current toxicity testing and risk assessment. ${ }^{3}$ Adverse outcome pathways (AOPs) can causally link molecular initiating events (MIEs), key events (KEs), and adverse outcomes (AOs) together to fill gaps of toxicological events and toxicity risk. ${ }^{4-7}$ Most developed AOPs are centralized in the AOP Wiki database (https://aopwiki.org/ ). To date, only 371 AOPs are available from AOP Wiki, and most of them are under development. However, manually curated development for an AOP network is a time-intensive process. ${ }^{8}$ Therefore, innovative strategies remain needed to develop and extend the AOP networks to identify the health effects of chemicals. ${ }^{9,10}$

More recently, toxicogenomics data mining and in silico techniques have been gradually developing as efficient approaches to speed up AOP development. ${ }^{11-13}$ Premier public resources (such as the Comparative Toxicogenomics Database (CTD), ToxCast, AOP Wiki database, etc.) can provide a chance to generate analytical toxic pathways. ${ }^{11,14-23}$ Oki and Edwards generated multiple AOP predictions by evaluating the associations of chemical-gene-disease data in

Received: December 21, 2020

Revised: February 26, 2021

Published: March 11, 2021 
the CTD. ${ }^{24}$ Jeong et al. developed AOPs using mammalian toxicity data obtained from ToxCast. ${ }^{21}$ Molecular dynamic (MD) simulation, an in silico techniques, can also be utilized to identify the MIEs in AOPs to directly relate chemical properties to activities. ${ }^{4,8,25-27}$ The previous study also successfully applied this approach to reveal the crucial role of $\mathrm{C}$ terminal $\mathrm{H} 12$ in the molecular interaction of bisphenol $\mathrm{S}$ (BPS) toward the thyroid hormone receptor $\beta(\mathrm{TR} \beta) .{ }^{28}$ As described above, the computational approach can identify useful biological data from public data sources to elucidate the unknown mechanisms of chemical toxicity. ${ }^{29}$ However, the biological rationality for the connections among KEs and adverse effects still needs to be validated by experimental data. ${ }^{30}$ Fortunately, diverse omics techniques can help to facilitate the link between molecular alterations and outcomes triggered by certain toxicants. ${ }^{31-33}$ Therefore, this study developed an approach to complete a preliminary AOP framework by utilizing database mining, multiomic techniques, and computational toxicology.

A large number of studies reported that triphenyl phosphate (TPP) was detected from environmental and human samples, indicating potential environmental and health risks. ${ }^{34,35}$ Previous toxicology research suggested that TPP is a potential endocrine disruptor, which is harmful to thyroid function. ${ }^{36-40}$ However, the known potential thyroid hormone-disrupting effects of TPP were scarce and the mechanism remained unclear. ${ }^{41}$ Additional studies are required to further explore the toxicity pathway of the thyroid dysfunction exposed by TPP.

In this study, the data of genes, pathways, and phenotypes were extracted by retrieving TPP from the chemicals module of the CTD database. The core gene was captured by analyzing interaction networks and transcriptomic results. Moreover, MD simulations revealed the changes of protein conformation encoded by the core gene to investigate the binding mechanisms. Additionally, transcriptome analysis also provided a comprehensive understanding of molecular mechanisms to identify the key events leading to thyroid pathway disorder. Finally, the data integrated from CTD, transcriptomics, and computational models facilitated the overall framework of the AOP. AOP descriptions can facilitate the understanding of thyroid hormone disrupting effects induced by TPP at multiple molecular levels and help to assess the health risk of emerging chemicals.

\section{MATERIALS AND METHODS}

TPP-Associated Gene Screening and Pathway Analysis. CTD, one of the publicly available and free databases, exhibits the relationships among gene products, molecules, and diseases. ${ }^{42}$ The four modules of CTD include toxicogenomic, chemical phenotype, disease, and exposure reflecting of the components. ${ }^{43}$ The genes related to TPP and thyroid disorder were selected from CTD (ctdbase.org) on June 06, 2019. The selected genes were submitted to the STRING start page (https://string-db.org/) to retrieve a network view. The network was visualized in Cytoscape 3.5.1 (http://www. cytoscape.org/download.php) to explore its potential molecular mechanisms. ${ }^{44}$ The cytohubba plugin in Cytoscape was applied to identify the core genes from the network map consisting of selected genes.

A generic AOP framework can include four components: an MIE that links a toxicant to a gene product, followed by a series of KEs, resulting in an $\mathrm{AO}$ that enhances an understanding at the population level (PO). ${ }^{42}$ TPP was input into the CTD database to screen TPPassociated genes, phenotypes, and other modules to explore the MIE and KEs. The content of four modules from CTD could be integrated to generate a predictive AOP.
MD Simulations and Trajectory Analysis. The conformational changes of the TR $\beta$ ligand binding domain (LBD) and TPP-TR $\beta$ were performed by MD simulations. The initial docking structure of TR $\beta$ was obtained by stripping the agonist ligand IH5 from the TR $\beta$ crystal structure with the PDB ID INAX selected from the RCSB Protein Data Bank (http://www.rcsb.org/pdb/home/home.do). The binding mode for TPP to TR $\beta$ LBD was performed by CDOCKER protocol in Discovery Studio 2.5.5 (Accelrys Software Inc.). ${ }^{45}$ The conventional MD simulations were further performed by Sander module implemented in Amber 14. ${ }^{28,46,47}$ Other details are shown in the Supporting Information. The cpptraj module implemented in Amber Tools 1.5 was used for conformational changes. The rootmean-square deviation of the $\alpha$ carbon atom (C $\alpha$ RMSD) could monitor the conformational changes. ${ }^{28,48,49}$

Reagents and Cell Culture. TPP (CAS no. 115-86-6, $\geq 99 \%$ ) was obtained from J\&K Chemical Co., Ltd. (Beijing, China). L02 cells (HL-7702, human normal liver cells) were purchased from Jiangsu Lvye Biotechnology Co., Ltd., and cultivated in Dulbecco's modified eagle medium (DMEM; Invitrogen) with $10 \%$ fetal bovine serum (FBS; HyClone Inc.), $100 \mathrm{u} / \mathrm{mL}$ penicillin, and $100 \mu \mathrm{g} / \mathrm{mL}$ streptomycin (HyClone Inc.) at $37{ }^{\circ} \mathrm{C}$ in a humidified $5 \% \mathrm{CO}_{2}$ atmosphere. ${ }^{50}$ The L02 cells were seeded, precultured for $24 \mathrm{~h}$, and then treated with TPP (final concentrations were 20 and $200 \mu \mathrm{M}$ ) in dimethyl sulfoxide (DMSO), together with control $(<0.1 \% \mathrm{DMSO})$, for $24 \mathrm{~h}$ to test related indicators (i.e., transcriptional expression, cell proliferation, cell apoptosis, and cell cycle). More details are shown in the Supporting Information.

Transcriptomic Analysis and Quantitative Real-Time PCR (qRT-PCR) Validation. Total RNA of L02 cells was isolated by using the RNA extraction kit. Illumina sequencing technology was used to screen the differentially expressed genes (DEGs) in three groups following manufacturer's instructions. qRT-PCR was performed on independently generated samples from L02 cells exposed at different concentrations of TPP. Primers for qRT-PCR were searched in Primer Bank (https://pga.mgh.harvard.edu/primerbank/index.html) and synthesized by Sangon Biotech. cDNAs were reverse transcribed from $3 \mu \mathrm{g}$ of total RNA using the PrimeScript RT reagent Kit (Takara, Da Lian, China) and qRT-PCR analyses were performed on an ABI PRISM 7500 Real-Time PCR System (Applied Biosystems, USA). The $\beta$-actin gene was used as the housekeeping gene to normalize the expression data. Each qRT-PCR experiment was repeated three times with three to six replicates per line in each experiment. The relative expressions of genes were calculated using the $2^{-\Delta \Delta C t}$ method. The gene-specific primers are listed in supplemental Table S1. More details are shown in the Supporting Information.

Statistical Analysis. All experiments were repeated at least three times with three to six replicates, and the results were expressed as the mean \pm standard deviation. The normality and homogeneity of variance were analyzed by Levene's test. Significance level was performed by one-way analysis of variance (ANOVA) followed by Tukey's tests. The statistical analysis was performed by SPSS statistical software (version 18.0, SPSS, Inc., Chicago, IL, USA).

\section{RESULTS}

Screening and Capturing of Core Genes from CTD. There are 186 genes related to TPP in the gene module in CTD (Table S2). Among them, 15 genes (THRB, THRA, TTR, TSHR, TSHB, GPBAR1, RXRA, TP53, GPX1, BMP4, GADD45A, DIO1, TPO, ESR1, and SLC5AS) associated with thyroid hormone disrupting effects were captured by taking their genes-diseases information and chemical (TPP)-genes data (Figure 1). As shown in Figure 1A, the four genes (THRB, $T S H B, T S H R$, and TPO) with deep red were supposed to be the key genes in thyroid signaling disorders by network analysis. THRB was also the expression gene in both transcriptome analyses and CTD retrieval (Figure 1B and Table S3). As a result, THRB was extrapolated as initial target 


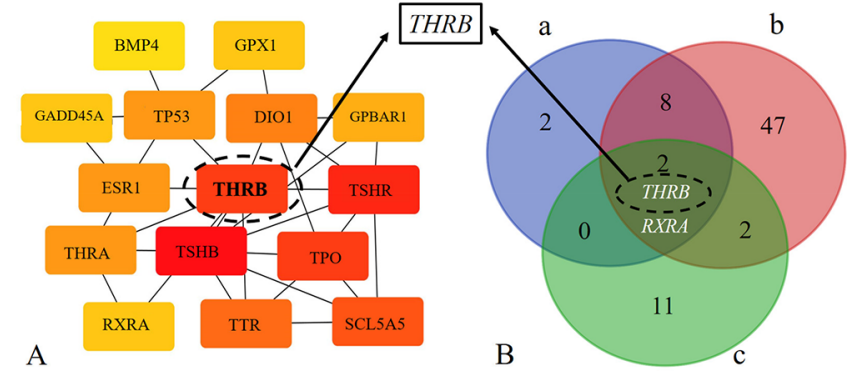

Figure 1. Key genes associated with thyroid hormone disrupting effects. (A) Interaction network showing the relationship among genes associated with 15 genes in thyroid hormone disorder related to TPP. Nodes represent single genes, and edges indicate either protein-protein or protein-DNA interactions. (B) Coexpressed genes between transcriptome and database induced by TPP: (a) DEGs involved in the thyroid signal pathway induced by $20 \mu \mathrm{M}$ TPP; (b) DEGs involved in the thyroid signal pathway induced by $200 \mu \mathrm{M}$ TPP; (c) genes related to TPP from the CTD database associated with the thyroid signal pathway.

gene in interfering with thyroid function from database and transcriptomics studies.

Molecular Dynamics Analysis. The computational toxicology approach could further provide the dynamic behavior and conformational space of chemical binding to TR to explore the molecular mechanisms which influenced the transcriptional pathways. ${ }^{51,52}$ TPP disturbed conformational changes to affect the structural stability of $\operatorname{TR} \beta \operatorname{LBD}$ in comparison to ligand free $\operatorname{TR} \beta$ (Figure $2 \mathrm{~B}$ ). The relative RMSD fluctuations for the backbone atoms of TPP molecules and TR complexes were less than $0.5 \mathrm{~nm}$ after $6 \mathrm{~ns}$, indicating that TPP bound to LBD reached steady state. ${ }^{26}$ The stable state during the simulation time suggested that TPP could induce transcriptional activation of $\mathrm{TR}^{26}$ In addition, the averaged root-mean-square deviation of $\alpha$ carbon atoms ( $\mathrm{C} \alpha$ RMSD) for the complex of TR $\beta$ LBD with TPP (2.39 $\AA$ ) was higher than that for apo $\operatorname{TR} \beta \operatorname{LBD}(1.97 \AA)$, which suggested conformational changes of $\operatorname{TR} \beta$ LBD induced by TPP (Figure 2B). TPP could form hydrogen bonds with residues of Asn121/Arg72 and $\pi$ bonds with residues of Asn121, Arg72, Arg106, Ala69, Met103, Leu120, Gly122, and Thr22 to exhibit a binding mode to $\mathrm{TR} \beta$ LBD (Figure 2C,D). These bonds locked the ligands to the binding site. The C-terminal Helix 12 (H12) of TPP-TR $\beta$ LBD underwent repositioning to lock TPP into the binding pocket compared with the apo-TR $\beta$ structure (Figure 2A). ${ }^{53}$ The altered position of $\mathrm{H} 12$ induced by the binding of TPP could be related to their potential disruption of transcriptional activity of TR. Thus, the interactions of related events in the $\operatorname{TR} \beta$ receptor signaling pathway deserved further study.

Transcriptional Responses. Transcriptional analysis revealed the interference mechanisms of the thyroid hormone signaling pathway at different exposure concentrations (20 and $200 \mu \mathrm{M})$ (Figure $3 \mathrm{~A})$. A low concentration $(20 \mu \mathrm{M})$ of TPP could increase the expression of THRB, RXRA, and PIK3R3. And, it influenced the formation of heterodimers with the retinoid X receptor (RXR), decreasing the expression of TP53 and NOTCH1 (apoptosis regulating gene). The $20 \mu \mathrm{M}$ TPP increased the expression of deiodinase type 2 (DIO2) to convert T4 into more active $\mathrm{T} 3$ and stabilized thyroid function. ${ }^{54-56}$

When the exposure concentration of TPP increased to 200 $\mu \mathrm{M}$, the number of DEGs was increased (Figure S1) and

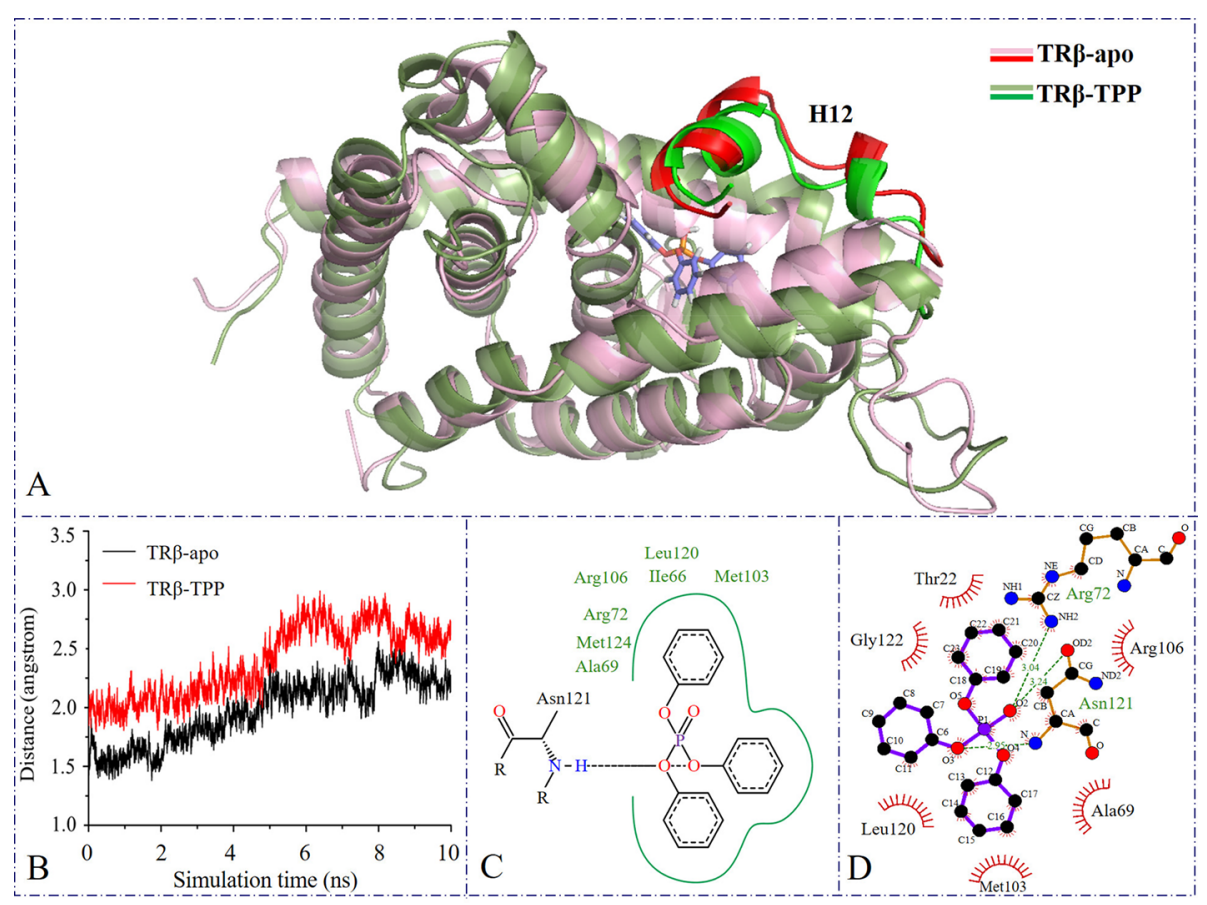

Figure 2. Configuration at the active site for TR $\beta$-TPP. (A) Measured distances between the carbon atom of TR $\beta$ LBD from 10 ns MD simulations. TR $\beta$ LBD in the apo form is black. The complexes with TPP are red, respectively. (B) Dynamic simulation results for TPP with the TR $\beta$ LBD. LBD in the apo form is green; the complexes with TPP are pink. (C) $\pi$ bond interactions between TPP with TR $\beta$ LBD. (D) Hydrophobic interactions between TPP in the TR $\beta$ LBD $(\bullet$ ligand bond, $\bullet$ nonligand bond, $-\infty$ hydrogen bond and its length, $\lambda_{\pi, 5}^{\text {His }}$ nonligand residues involved in hydrophobic contacts, corresponding atoms involved in hydrophobic contacts). 


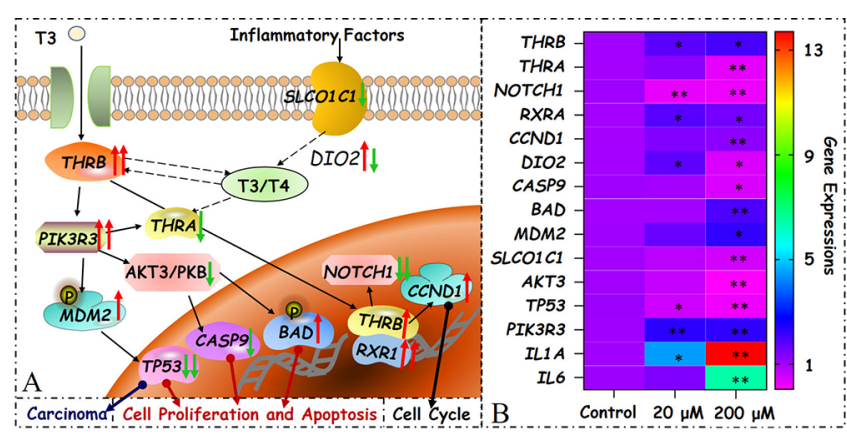

Figure 3. Expression and interaction of altered genes. (A) Schematic presentation of thyroid hormone pathways after exposure to 20 and $200 \mu \mathrm{M}$ TPP, respectively ( $\uparrow$ represented up-regulated genes; $\downarrow$ represented down-regulated genes; $\rightarrow$ represented the results of an adverse outcome). (B) Heat map visualizing the differential expression of genes. ${ }^{*}$ indicates $p<0.05$ compared with the control group. $* *$ indicates $p<0.01$ compared with the control group.

DEGs were significantly enriched in the cell cycle, apoptosis, cancer, and immune inflammation versus the $20 \mu \mathrm{M}$ TPPtreated group (Figure S2). In addition to influencing the pathway related to $20 \mu \mathrm{M}$ TPP, $200 \mu \mathrm{M}$ TPP also changed the expression of the PIK3R3 and AKT3 genes in the PI3/Akt pathway, increasing the expressions of $M D M 2, B A D$ and reducing the expressions of NOTCH1, DIO2, THRA, TP53, and CASP9 (Table S4). The down-regulated expression of DIO2 meant the inhibited conversion of T4 to T3, resulting in the low levels of $\mathrm{T} 3$ to affect thyroid function. The incidence of cancer was related to the differential expression of oncogene MDM2 and tumor suppressor gene TP53. The KEGG pathway analysis also showed that several cancer-related pathways (small cell cancer and colorectal cancer) were enriched in the $200 \mu \mathrm{M}$ TPP exposure group (Figure S3). The apoptosis regulating genes (CASP9, TP53, and BAD) were also significantly changed in the L02 cell. The inhibition of TP53 and Notch1 induces apoptosis via the caspase pathway. ${ }^{57,58}$ The death promoter $(B A D)$ was activated in the $200 \mu \mathrm{M}$ TPPtreated group, which could be stimulated by cellular apoptosis signals and activated the downstream apoptotic factor. ${ }^{59,60}$ The high concentration $(200 \mu \mathrm{M})$ of TPP affected more cell cycling-related gene expressions (CCND2 and CCND3). And TPP increased the DIO2 expression under $20 \mu \mathrm{M}$ TPP exposure but decreased the expression of DIO2 when the TPP concentration was $200 \mu \mathrm{M}$. The $200 \mu \mathrm{M}$ TPP caused immune stress to release more inflammatory factors (e.g., IL1A, IL6) which were involved in cell cycle and apoptosis. Furthermore, inflammatory factors could compete with $\mathrm{TH}$ to bind transthyretin (TTR), resulting in decreasing the expression of thyroxine transporter (SLCO1C1) (Table S4).

Transcriptome analysis indicated that cell apoptosis, cell cycle control, and cell proliferation were mainly presumed to be KEs at the cellular level in the toxicity pathway of thyroid hormone interference from TPP. In order to verify and complete the mechanism of thyroid hormone disorders caused by TPP, in vitro tests were utilized to further identify and supplement the KEs at the cellular level.

KE Supplement and Verification. Transcriptomic analysis showed that cell proliferation, cell apoptosis, and the cell cycle were important KEs at cellular and molecular levels. As shown in Table 1, the CTD covered 72 phenotypes related to TPP which could be divided into subcellular, cellular, and system KE levels by mapping onto diverse GO hierarchy. Cell
Table 1. Different System KEs of Prioritized 72 Phenotypes Related to TPP from CTD

\begin{tabular}{|c|c|c|}
\hline & biological process & category \\
\hline \multirow[t]{20}{*}{$\begin{array}{l}\text { KE1: } \\
\text { subcellular }\end{array}$} & positive regulation of glucose import & $\begin{array}{l}\text { carbohydrate } \\
\text { synthesis and } \\
\text { metabolism }\end{array}$ \\
\hline & triglyceride biosynthetic process & \multirow{6}{*}{$\begin{array}{l}\text { lipid synthesis and } \\
\text { metabolism }\end{array}$} \\
\hline & cholesterol biosynthetic process & \\
\hline & lipid biosynthetic process & \\
\hline & linoleic acid metabolic process & \\
\hline & alkaline phosphatase activity & \\
\hline & lipid catabolic process & \\
\hline & diacylglycerol biosynthetic process & \multirow[t]{13}{*}{ others } \\
\hline & lipid metabolic process & \\
\hline & progesterone biosynthetic process & \\
\hline & testosterone biosynthetic process & \\
\hline & $\begin{array}{l}\text { positive regulation of glutathione } \\
\text { peroxidase activity }\end{array}$ & \\
\hline & $\begin{array}{l}\text { glutathione derivative biosynthetic } \\
\text { process }\end{array}$ & \\
\hline & glutathione metabolic process & \\
\hline & glutathione biosynthetic process & \\
\hline & glutathione peroxidase activity & \\
\hline & glutathione transferase activity & \\
\hline & lysine decarboxylase activity & \\
\hline & $\begin{array}{l}\text { reactive oxygen species biosynthetic } \\
\text { process }\end{array}$ & \\
\hline & apoptotic DNA fragmentation & \\
\hline \multirow[t]{12}{*}{$\begin{array}{l}\text { KE2: } \\
\text { cellular }\end{array}$} & gluconeogenesis & $\begin{array}{l}\text { carbohydrate } \\
\text { synthesis and } \\
\text { metabolism }\end{array}$ \\
\hline & fat cell differentiation & \multirow{2}{*}{$\begin{array}{l}\text { lipid synthesis and } \\
\text { metabolism }\end{array}$} \\
\hline & $\begin{array}{l}\text { positive regulation of fat cell } \\
\text { differentiation }\end{array}$ & \\
\hline & cell death & \multirow{5}{*}{$\begin{array}{l}\text { cell proliferation and } \\
\text { apoptosis }\end{array}$} \\
\hline & positive regulation of cell proliferation & \\
\hline & positive regulation of cell death & \\
\hline & cell proliferation & \\
\hline & $\begin{array}{l}\text { positive regulation of fibroblast } \\
\text { proliferation }\end{array}$ & \\
\hline & estradiol secretion & \multirow{4}{*}{$\begin{array}{l}\text { hormone secretion } \\
\text { and regulation }\end{array}$} \\
\hline & androgen secretion & \\
\hline & $\begin{array}{l}\text { positive regulation of intracellular } \\
\text { estrogen receptor signaling pathway }\end{array}$ & \\
\hline & $\begin{array}{l}\text { positive regulation of testosterone } \\
\text { secretion }\end{array}$ & \\
\hline \multirow{11}{*}{$\begin{array}{l}\text { KE3: } \\
\text { system }\end{array}$} & positive regulation of lipid storage & \multirow{3}{*}{$\begin{array}{l}\text { lipid synthesis and } \\
\text { metabolism }\end{array}$} \\
\hline & $\begin{array}{l}\text { positive regulation of adipose tissue } \\
\text { development }\end{array}$ & \\
\hline & lipid droplet formation & \\
\hline & heart looping & \multirow{6}{*}{$\begin{array}{l}\text { development and } \\
\text { organ regulation }\end{array}$} \\
\hline & negative regulation of heart rate & \\
\hline & $\begin{array}{l}\text { regulation of heart rate by cardiac } \\
\text { conduction }\end{array}$ & \\
\hline & embryo development & \\
\hline & pericardium morphogenesis & \\
\hline & regulation of heart rate & \\
\hline & nematode larval development & \multirow[t]{2}{*}{ others } \\
\hline & sexual reproduction & \\
\hline
\end{tabular}

proliferation was also the KEs annotated to THRB by the screening database (Table 1). These KEs were further verified by using in vitro approaches. The cytotoxicity of TPP was assessed by apoptosis rate, proliferation rate, and cell cycle dysregulation after $24 \mathrm{~h}$ of incubation. 
The cell relative growth rate decreased in the $200 \mu \mathrm{M}$ TPP treated group $(p<0.05)$ (Figure 4A). The apoptosis rate was

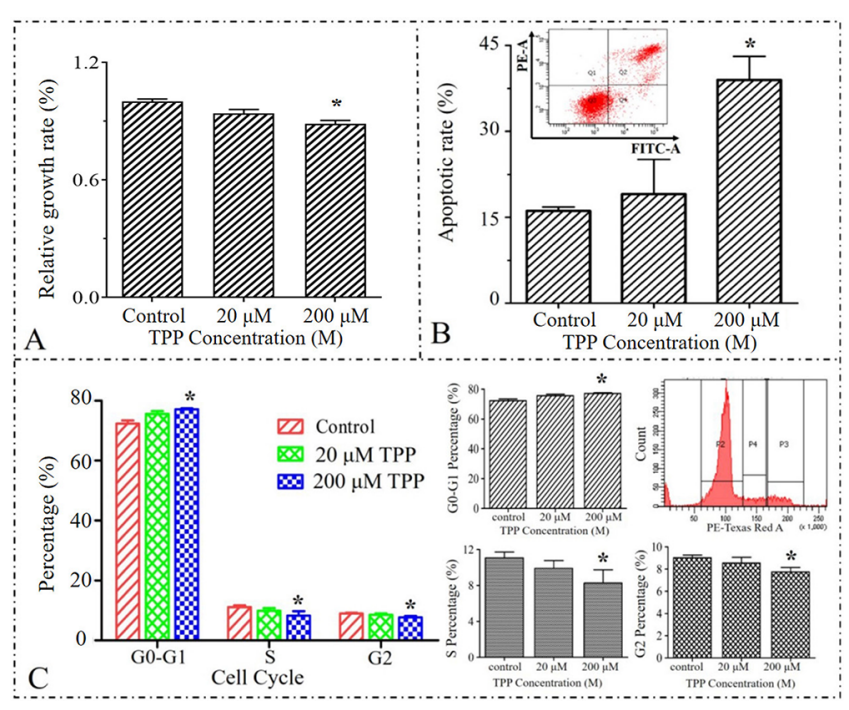

Figure 4. Cytotoxicity of L02 induced by TPP: (A) cell proliferation; (B) cell apoptosis; (C) cell cycle of L02 after exposed to TPP. * indicates $p<0.05$ compared with the control group.

significantly increased in L02 cells exposed to $200 \mu \mathrm{M}$ TPP for $24 \mathrm{~h}(p<0.05)$ (Figure 4B). However, no significant differences were observed between the group treated with the $20 \mu \mathrm{M}$ TPP and the control. During $24 \mathrm{~h}$ of treatment with $200 \mu \mathrm{M}$ TPP, the G1 peak of the cells was increased, and the $S$ phase and G2 peak were decreased (Figure 4C). The effect of TPP on the cell cycle and apoptosis was found to be concentration-dependent. TPP could affect cell cycle distribution, cause G0-G1 phase arrest and induce L02 cell apoptosis. As a result, the AOP was completed through the results of the multiple techniques.

\section{DISCUSSION}

Global Chemicals Outlook II shows that the size of the global chemical industry exceeds 5 trillion dollars and that global chemical production is expected to double by $2030 .{ }^{61}$ In the absence of toxicology data on the majority of chemicals, urgent action and effective methods are needed to assess the adverse impacts of chemicals. ${ }^{62}$ The AOPs are a promising approach to reveal the toxicity mechanism, evaluate the potential risks, and monitor emerging contaminants in the 2lst century. However, the AOP developments of chemicals with unknown or poorly understood effects are time-consuming and inefficient if the methods still rely heavily on biological experimental analysis. ${ }^{19,20,63}$ Fortunately, computational models, toxicogenomic methods (toxicological and systems biological information), and toxicological databases (AOP Wiki, CTD, etc.) have gradually been used to speed up AOP development. ${ }^{19-22}$ Previous studies have emphasized that transcriptomics and in vitro studies could help to identify MIEs/KEs, supplement the AOP input, and reduce uncertainties. ${ }^{12,64}$ The Organization for Economic Co-operation and Development (OECD) also advocated the integration of in vitro, in vivo, and computer models to construct relationships among MIEs, KEs, and AOs to develop AOPs. ${ }^{65}$ Hence, this study integrated existing databases, omics technology, and a computer model to complete an AOP framework which used the thyroid hormone interference with TPP as a case study (Figure 5).

TPP, one of the typical emerging contaminants, had been identified as one of the potential endocrine-disrupting compounds that affect thyroid hormone levels. ${ }^{66,67}$ TR was considered as the important targets involved in the chemical perturbations of thyroid disruption..$^{27,28,41,68,69}$ However, no AOP had been structured to describe the causal sequences from TR activation (an MIE) to transcriptomic changes, cellular phenotypes, and diseases in AOP Wiki. Therefore, more research about the potential human health effects of TPP needs to be conducted.

As shown in Figure 1, the THRB gene was identified as the key gene by both detections of gene expression at the transcription level and CTD mining. TR $\beta$ (encoded by the THRB gene) could bind with TPP by hydrogen-bonding action and $\pi-\pi$ interaction to change its conformation (conformational change at H12) (Figure 2). Receptor-ligand binding is considered as the usual pathway in the endocrinedisrupting effects of chemicals. ${ }^{45}$ The conformational changes of TR $\beta$ induced by contaminants may consequently affect the transcriptional activity of $\operatorname{TR} \beta$, leading to the activation of downstream signal pathways and thyroid hormone disruption, which was consistent with the previous experimental results. $^{28,36,41,64}$ In this research, the alternative $\mathrm{TR} \beta \mathrm{H} 12$ position was indicated as an MIE.

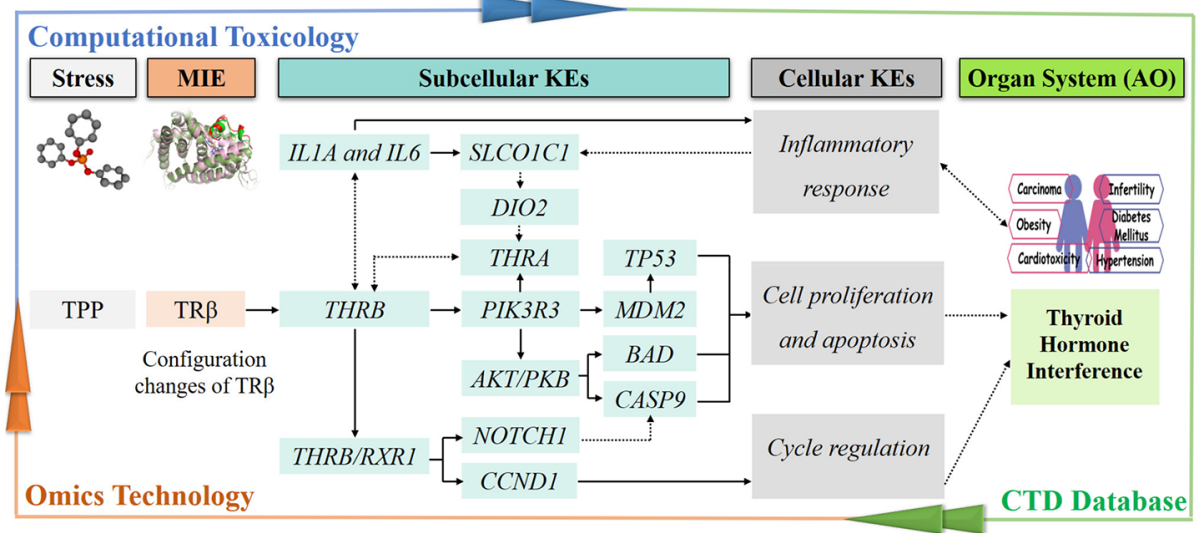

Figure 5. Primary AOP framework developed by multiple techniques (computational toxicology, toxicogenomics data mining, and omics techniques). 
The conformation change of $\operatorname{TR} \beta$ could also affect the expression of RXRA. RXRA was up-regulated significantly ( $p<$ 0.05 ) in both TPP-treated groups (Figure 3 and Table S4). The formation of dimer partners between TR and retinoid $X$ receptor (RXR) could alter ligand-dependent signaling pathways. $^{28,70,71}$ Moreover, in the $\operatorname{TR} \beta$-mediated pathways, the transcriptional activities of CCND1 and NOTCH genes involved in cell cycle control and cell communication were also altered (Figure 3B). Wang et al. ${ }^{72}$ found that CCND1 was the most significant gene in thyroid carcinoma and thyroid adenoma. And, Bièche et al. ${ }^{73}$ also suggested that the CCND1 gene could serve an early role in thyroid tumorigenesis. The NOTCH gene played an important role in cell-cell communication, immune response, and cancer regulation, ${ }^{74-78}$ which was consistent with the results of GO and KEGG pathway enrichment analysis (Figures S2 and S3).

As the concentration of TPP increased, there was a downregulation of $\mathrm{DIO} 2$ (Figure $3 \mathrm{~B}$ ) which was related to the thyroid hormone $(\mathrm{TH})$ metabolism and $\mathrm{T} 3$ level regulation. $^{36,79}$ DIO2 could convert $\mathrm{T} 4$ into more active $\mathrm{T} 3$ to stabilize thyroid function in the catalytic deiodination of external cyclic iodine. ${ }^{54-56}$ The down-regulated expression of $\mathrm{DIO} 2$ meant the reduced conversion of $\mathrm{T} 4$ to $\mathrm{T} 3$, which might be related to the conformational change of TPP binding TR $\beta$. It was speculated that TPP could exhibit $\operatorname{TR} \beta$ agonistic activity.

The $200 \mu \mathrm{M}$ TPP changed the expressions of apoptoticrelated genes (CASP9, TP53, and BAD) (Table S4). Moreover, this concentration of TPP caused significant immune stress, resulting in released inflammatory cytokine (e.g., IL1A and IL6) which involved in the cycle dysregulation and apoptosis (Figure 3A). As shown in Figure 4B, $200 \mu \mathrm{M}$ TPP caused significant apoptosis compared to the low concentration group and control group. The PI3K/Akt pathway implied an important function in cellular signal transduction and regulation processes. ${ }^{80}$ The activated PI $3 K$ has an important role in the inhibition of apoptosis. ${ }^{81}$ And, Akt can mediate the cell-survival response which is dependent on PI3K. ${ }^{81}$ The activated PI3K/Akt and ERK pathways could disorder the HPT axis by up-regulating TR $\beta 1$ expressions. ${ }^{80}$ The inflammatory factors could not only cause apoptosis but also compete with $\mathrm{TH}$ to bind $\mathrm{TTR},{ }^{82}$ resulting in the decrease of SLCO1C1 expression and $\mathrm{TH}$ transport.

From what had been discussed above, the details of the AOP were summarized as follow. The critical MIE was the conformational changes of $\operatorname{TR} \beta$ induced by TPP binding. This alteration could affect a series of critical transcriptional regulations that mainly associated with cycle regulation (CCND1), inflammatory response (IL1A and IL6) and cell proliferation and apoptosis (BAD, TP53, and CASP9) (subcellular KEs). And then, critical intermediate events (cell cycle, inflammatory response, cell proliferation, and apoptosis) at cellular levels were identified by the results of CTD retrieval and the in vitro test. These KEs ultimately resulted in thyroid toxicity through molecular cause-effect relationships to supplement the AOP framework (Figure 5).

\section{CONCLUSION}

This study innovatively integrated the computational toxicology, toxicogenomic data mining, and high throughput omics techniques to identify the MIE and construct the relationships among MIEs, KEs, and $\mathrm{AO}$ in thyroid hormone interference with TPP. Although the developed AOP was primary, it still provided a novel way to improve the extension of the AOP framework for emerging synthetic chemicals that lacked toxicology data. Moreover, this combination of available technologies could assess the potential health hazards for contaminants across multibiological levels in an efficient and economical way.

\section{ASSOCIATED CONTENT}

\section{Supporting Information}

The Supporting Information is available free of charge at https://pubs.acs.org/doi/10.1021/acssuschemeng.0c09196.

Additional information about materials and methods. Transcriptional responses and pathway analysis (PDF)

\section{AUTHOR INFORMATION}

\section{Corresponding Authors}

Fei Li - CAS Key Laboratory of Coastal Environmental Processes and Ecological Remediation, Yantai Institute of Coastal Zone Research (YIC), Chinese Academy of Sciences (CAS); Shandong Key Laboratory of Coastal Environmental Processes, YICCAS, Yantai 264003, P. R. China; (1) orcid.org/0000-0001-7386-0835; Phone: 86-5352109189; Email: fli@yic.ac.cn; Fax: 86-535-2109000

Huifeng Wu - CAS Key Laboratory of Coastal Environmental Processes and Ecological Remediation, Yantai Institute of Coastal Zone Research (YIC), Chinese Academy of Sciences (CAS); Shandong Key Laboratory of Coastal Environmental Processes, YICCAS, Yantai 264003, P. R. China; Center for Ocean Mega-Science, Chinese Academy of Sciences, Qingdao 266071, P. R. China; Phone: 86-535-2109190;

Email: hfwu@yic.ac.cn; Fax: 86-535-2109000

\section{Authors}

Xiaoqing Wang - CAS Key Laboratory of Coastal Environmental Processes and Ecological Remediation, Yantai Institute of Coastal Zone Research (YIC), Chinese Academy of Sciences (CAS); Shandong Key Laboratory of Coastal Environmental Processes, YICCAS, Yantai 264003, P. R. China; University of Chinese Academy of Sciences, Beijing 100049, P. R. China

Jingwen Chen - Key Laboratory of Industrial Ecology and Environmental Engineering (MOE), School of Environmental Science and Technology, Dalian University of Technology, Dalian 116024, China; (1) orcid.org/0000-0002-5756-3336

Chenglong Ji - CAS Key Laboratory of Coastal Environmental Processes and Ecological Remediation, Yantai Institute of Coastal Zone Research (YIC), Chinese Academy of Sciences (CAS); Shandong Key Laboratory of Coastal Environmental Processes, YICCAS, Yantai 264003, P. R. China; Center for Ocean Mega-Science, Chinese Academy of Sciences, Qingdao 266071, P. R. China

Complete contact information is available at:

https://pubs.acs.org/10.1021/acssuschemeng.0c09196

\section{Funding}

This research was supported by the Yantai Science and Technology Development Plan (2020MSGY060), National Natural Science Foundation of China (21677173, 41530642), and the Youth Innovation Promotion Association CAS (2017255).

\section{Notes}

The authors declare no competing financial interest. 


\section{REFERENCES}

(1) Wang, Z.; Walker, G. W.; Muir, D. C. G.; Nagatani-Yoshida, K. Toward a global understanding of chemical pollution: A first comprehensive analysis of national and regional chemical inventories. Environ. Sci. Technol. 2020, 54 (5), 2575-2584.

(2) Perkins, E. J.; Ashauer, R.; Burgoon, L.; Conolly, R.; Landesmann, B.; Mackay, C.; Murphy, C. A.; Pollesch, N.; Wheeler, J. R.; Zupanic, A.; Scholz, S. Building and applying quantitative adverse outcome pathway models for chemical hazard and risk assessment. Environ. Toxicol. Chem. 2019, 38 (9), 1850-1865.

(3) Hvastkovs, E. G.; Rusling, J. F. State-of-the-art metabolic toxicity screening and pathway evaluation. Anal. Chem. 2016, 88 (9), 45844599.

(4) Allen, T. E.; Goodman, J. M.; Gutsell, S.; Russell, P. J. Defining molecular initiating events in the adverse outcome pathway framework for risk assessment. Chem. Res. Toxicol. 2014, 27 (12), 2100-2012.

(5) Delrue, N.; Sachana, M.; Sakuratani, Y.; Gourmelon, A.; Leinala, E.; Diderich, R. The adverse outcome pathway concept: A basis for developing regulatory decision-making tools. ATLA, Altern. Lab. Anim. 2016, 44 (5), 417-429.

(6) Kramer, V. J.; Etterson, M. A.; Hecker, M.; Murphy, C. A.; Roesijadi, G.; Spade, D. J.; Spromberg, J. A.; Wang, M.; Ankley, G. T. Adverse outcome pathways and ecological risk assessment: Bridging to population-level effects. Environ. Toxicol. Chem. 2011, 30 (1), 6476.

(7) Perkins, E. J.; Antczak, P.; Burgoon, L.; Falciani, F.; GarciaReyero, N.; Gutsell, S.; Hodges, G.; Kienzler, A.; Knapen, D.; McBride, M.; Willett, C. Adverse outcome pathways for regulatory applications: Examination of four case studies with different degrees of completeness and scientific confidence. Toxicol. Sci. 2015, 148 (1), $14-25$.

(8) Bell, S. M.; Angrish, M. M.; Wood, C. E.; Edwards, S. W. Integrating publicly available data to generate computationally predicted adverse outcome pathways for fatty liver. Toxicol. Sci. 2016, 150 (2), 510-520.

(9) Madden, J. C.; Rogiers, V.; Vinken, M. Application of in silico and in vitro methods in the development of adverse outcome pathway constructs in wildlife. Philos. Trans. R. Soc., B 2014, 369 (1656), 20130584 .

(10) Rugard, M.; Coumoul, X.; Carvaillo, J. C.; Barouki, R.; Audouze, K. Deciphering adverse outcome pathway network linked to bisphenol $\mathrm{F}$ using text mining and systems toxicology approaches. Toxicol. Sci. 2020, 173 (1), 32-40.

(11) Jin, Y.; Feng, M.; Ma, W.; Wei, Y.; Qi, G.; Luo, J.; Xu, L.; Li, X.; Li, C.; Wang, Y.; Li, D.; Chen, J.; Zhao, Y.; Hou, Y.; Zhao, Q.; Jiang, L.; Xie, M.; Zheng, Y.; Yu, D. A toxicity pathway-oriented approach to develop adverse outcome pathway: AHR activation as a case study. Environ. Pollut. 2021, 268, 115733.

(12) Vinken, M. Omics-based input and output in the development and use of adverse outcome pathways. Curr. Opin. Toxicol. 2019, 18, $8-12$.

(13) Ciallella, H. L.; Zhu, H. Advancing computational toxicology in the big data era by artificial intelligence: Data-driven and mechanismdriven modeling for chemical toxicity. Chem. Res. Toxicol. 2019, 32 (4), 536-547.

(14) Mortensen, H. M.; Chamberlin, J.; Joubert, B.; Angrish, M.; Sipes, N.; Lee, J. S.; Euling, S. Y. Leveraging human genetic and adverse outcome pathway (AOP) data to inform susceptibility in human health risk assessment. Mamm. Genome 2018, 29 (1), 190204.

(15) Nymark, P.; Rieswijk, L.; Ehrhart, F.; Jeliazkova, N.; Tsiliki, G.; Sarimveis, H.; Evelo, C. T.; Hongisto, V.; Kohonen, P.; Willighagen, E.; Grafström, R. C. A data fusion pipeline for generating and enriching adverse outcome pathway descriptions. Toxicol. Sci. 2018, 162 (1), 264-275.

(16) Oki, N. O.; Nelms, M. D.; Bell, S. M.; Mortensen, H. M.; Edwards, S. W. Accelerating adverse outcome pathway development using publicly available data sources. Curr. Envir. Health Rpt. 2016, 3 (1), 53-63.

(17) Villeneuve, D. L.; Crump, D.; Garcia-Reyero, N.; Hecker, M.; Hutchinson, T. H.; LaLone, C. A.; Landesmann, B.; Lettieri, T.; Munn, S.; Nepelska, M.; Ottinger, M. A.; Vergauwen, L.; Whelan, M. Adverse outcome pathway (AOP) development I: Strategies and principles. Toxicol. Sci. 2014, 142 (2), 312-320.

(18) Villeneuve, D. L.; Crump, D.; Garcia-Reyero, N.; Hecker, M.; Hutchinson, T. H.; LaLone, C. A.; Landesmann, B.; Lettieri, T.; Munn, S.; Nepelska, M.; Ottinger, M. A.; Vergauwen, L.; Whelan, M. Adverse outcome pathway development II: Best practices. Toxicol. Sci. 2014, 142 (2), 321-330.

(19) Chai, Z.; Zhao, C.; Jin, Y.; Wang, Y.; Zou, P.; Ling, X.; Yang, H.; Zhou, N.; Chen, Q.; Sun, L.; Chen, W.; Ao, L.; Cao, J.; Liu, J. Generating adverse outcome pathway (AOP) of inorganic arsenicinduced adult male reproductive impairment via integration of phenotypic analysis in comparative toxicogenomics database (CTD) and AOP wiki. Toxicol. Appl. Pharmacol. 2021, 411, 115370.

(20) Kim, Y.; Jeong, J.; Lee, S.; Choi, I.; Choi, J. Identification of adverse outcome pathway related to high-density polyethylene microplastics exposure: Caenorhabditis elegans transcription factor RNAi screening and zebrafish study. J. Hazard. Mater. 2020, 388, 121725 .

(21) Jeong, J.; Choi, J. Development of AOP relevant to microplastics based on toxicity mechanisms of chemical additives using ToxCast and deep learning models combined approach. Environ. Int. 2020, 137, 105557.

(22) Blalock, B. J.; Robinson, W. E.; Loguinov, A.; Vulpe, C. D.; Krick, K. S.; Poynton, H. C. Transcriptomic and Network Analyses Reveal Mechanistic-Based Biomarkers of Endocrine Disruption in the Marine Mussel, Mytilus edulis. Environ. Sci. Technol. 2018, 52 (16), 9419-9430.

(23) Carusi, A.; Davies, M. R.; De Grandis, G.; Escher, B. I.; Hodges, G.; Leung, K. M. Y.; Whelan, M.; Willett, C.; Ankley, G. T. Harvesting the promise of AOPs: An assessment and recommendations. Sci. Total Environ. 2018, 628-629, 1542-1556.

(24) Oki, N. O.; Edwards, S. W. An integrative data mining approach to identifying adverse outcome pathway signatures. Toxicology 2016, 350-352, 49-61.

(25) OECD. Guidance document on the reporting of defined approaches and individual information sources to be used within integrated approaches to testing and assessment (IATA) for skin sensitisation. 2017. https://www.oecd.org/publications/guidancedocument-on-the-reporting-of-defined-approaches-and-individualinformation-sources-to-be-used-within-integrated-9789264279285-en. htm (accessed 18 July 2020).

(26) Wu, Y.; Su, G.; Tang, S.; Liu, W.; Ma, Z.; Zheng, X.; Liu, H.; $\mathrm{Yu}, \mathrm{H}$. The combination of in silico and in vivo approaches for the investigation of disrupting effects of tris (2-chloroethyl) phosphate (TCEP) toward core receptors of zebrafish. Chemosphere 2017, 168, $122-130$.

(27) Lu, L.; Wu, H.; Cui, S.; Zhan, T.; Zhang, C.; Lu, S.; Liu, W.; Zhuang, S. Pentabromoethylbenzene exposure induces transcriptome aberration and thyroid dysfunction: In vitro, in silico, and in vivo investigations. Environ. Sci. Technol. 2020, 54 (19), 12335-12344.

(28) Lu, L.; Zhan, T.; Ma, M.; Xu, C.; Wang, J.; Zhang, C.; Liu, W.; Zhuang, $\mathrm{S}$. Thyroid disruption by bisphenol $\mathrm{S}$ analogues via thyroid hormone receptor $\beta$ : In vitro, in vivo, and molecular dynamics simulation study. Environ. Sci. Technol. 2018, 52 (11), 6617-6625.

(29) Russo, D. P.; Strickland, J.; Karmaus, A. L.; Wang, W.; Shende, S.; Hartung, T.; Aleksunes, L. M.; Zhu, H. Nonanimal models for acute toxicity evaluations: Applying data-driven profiling and readacross. Environ. Health Perspect. 2019, 127 (4), 47001.

(30) Aguayo-Orozco, A.; Taboureau, O.; Brunak, S. The use of systems biology in chemical risk assessment. Curr. Opin. Toxicol. 2019, 15, 48-54.

(31) Groh, K. J.; Carvalho, R. N.; Chipman, J. K.; Denslow, N. D.; Halder, M.; Murphy, C. A.; Roelofs, D.; Rolaki, A.; Schirmer, K.; Watanabe, K. H. Development and application of the adverse 
outcome pathway framework for understanding and predicting chronic toxicity: I. Challenges and research needs in ecotoxicology. Chemosphere 2015, 120, 764-777.

(32) Groh, K. J.; Carvalho, R. N.; Chipman, J. K.; Denslow, N. D.; Halder, M.; Murphy, C. A.; Roelofs, D.; Rolaki, A.; Schirmer, K.; Watanabe, K. H. Development and application of the adverse outcome pathway framework for understanding and predicting chronic toxicity: II. A focus on growth impairment in fish. Chemosphere 2015, 120, 778-792.

(33) Sturla, S. J.; Boobis, A. R.; FitzGerald, R. E.; Hoeng, J.; Kavlock, R. J.; Schirmer, K.; Whelan, M.; Wilks, M. F.; Peitsch, M. C. Systems toxicology: From basic research to risk assessment. Chem. Res. Toxicol. 2014, 27 (3), 314-329.

(34) Carignan, C. C.; McClean, M. D.; Cooper, E. M.; Watkins, D. J.; Fraser, A. J.; Heiger-Bernays, W.; Stapleton, H. M.; Webster, T. F. Predictors of tris(1,3-dichloro-2-propyl) phosphate metabolite in the urine of office workers. Environ. Int. 2013, 55, 56-61.

(35) Chen, Y.; Cao, Z.; Covaci, A.; Li, C.; Cui, X. Novel and legacy flame retardants in paired human fingernails and indoor dust samples. Environ. Int. 2019, 133, 105227.

(36) Kim, S.; Jung, J.; Lee, I.; Jung, D.; Youn, H.; Choi, K. Thyroid disruption by triphenyl phosphate, an organophosphate flame retardant, in zebrafish (Danio rerio) embryos/larvae, and in GH3 and FRTL-5 cell lines. Aquat. Toxicol. 2015, 160, 188-196.

(37) Kojima, H.; Takeuchi, S.; Itoh, T.; Iida, M.; Kobayashi, S.; Yoshida, T. In vitro endocrine disruption potential of organophosphate flame retardants via human nuclear receptors. Toxicology 2013, 314 (1), 76-83.

(38) Liu, C.; Wang, Q.; Liang, K.; Liu, J.; Zhou, B.; Zhang, X.; Liu, H.; Giesy, J. P.; Yu, H. Effects of tris(1,3-dichloro-2-propyl) phosphate and triphenyl phosphate on receptor-associated mRNA expression in zebrafish embryos/larvae. Aquat. Toxicol. 2013, 128129, 147-157.

(39) Liu, X.; Jung, D.; Jo, A.; Ji, K.; Moon, H. B.; Choi, K. Longterm exposure to triphenylphosphate alters hormone balance and HPG, HPI, and HPT gene expression in zebrafish (Danio rerio). Environ. Toxicol. Chem. 2016, 35 (9), 2288-2296.

(40) Meeker, J. D.; Stapleton, H. M. House dust concentrations of organophosphate flame retardants in relation to hormone levels and semen quality parameters. Environ. Health Perspect. 2010, 118 (3), $318-323$.

(41) Zhang, Q.; Ji, C.; Yin, X.; Yan, L.; Lu, M.; Zhao, M. Thyroid hormone-disrupting activity and ecological risk assessment of phosphorus-containing flame retardants by in vitro, in vivo and in silico approaches. Environ. Pollut. 2016, 210, 27-33.

(42) Davis, A. P.; Grondin, C. J.; Johnson, R. J.; Sciaky, D.; McMorran, R.; Wiegers, J.; Wiegers, T. C.; Mattingly, C. J. The Comparative Toxicogenomics Database: Update 2019. Nucleic Acids Res. 2019, 47 (D1), D948-D954.

(43) Davis, A. P.; Wiegers, T. C.; Wiegers, J.; Johnson, R. J.; Sciaky, D.; Grondin, C. J.; Mattingly, C. J. Chemical-induced phenotypes at CTD help inform the predisease state and construct adverse outcome pathways. Toxicol. Sci. 2018, 165 (1), 145-156.

(44) Jonsson, P. F.; Cavanna, T.; Zicha, D.; Bates, P. A. Cluster analysis of networks generated through homology: automatic identification of important protein communities involved in cancer metastasis. BMC Bioinf. 2006, 7, 2-2.

(45) Yang, X.; Lyakurwa, F.; Xie, H.; Chen, J.; Li, X.; Qiao, X.; Cai, $\mathrm{X}$. Different binding mechanisms of neutral and anionic poly-/ perfluorinated chemicals to human transthyretin revealed by in silico models. Chemosphere 2017, 182, 574-583.

(46) Case, D. A.; Babin, V.; Berryman, J.; Betz, R. M.; Cai, Q.; Cerutti, D. S.; Cheatham Iii, T. E.; Darden, T. A.; Duke, R. E.; Gohlke, H., Goetz, A. W. Amber 14; 2014; https://ambermd.org (accessed 29 July 2020).

(47) Wang, F. F.; Yang, W.; Shi, Y. H.; Cheng, X. R.; Le, G. W. Structure-based approach for the study of thyroid hormone receptor binding affinity and subtype selectivity. J. Biomol. Struct. Dyn. 2016, 34 (10), 2251-2267.
(48) Chen, Q.; Wang, X.; Shi, W.; Yu, H.; Zhang, X.; Giesy, J. P. Identification of thyroid hormone disruptors among HO-PBDEs: In vitro investigations and coregulator involved simulations. Environ. Sci. Technol. 2016, 50 (22), 12429-12438.

(49) Wu, H.; Lu, L.; Chen, J.; Zhang, C.; Liu, W.; Zhuang, S. Inhibited nitric oxide production of human endothelial nitric oxide synthase by nitrated and oxygenated polycyclic aromatic hydrocarbons. Environ. Sci. Technol. 2020, 54 (5), 2922-2930.

(50) Hu, W.; Gao, F.; Zhang, H.; Hiromori, Y.; Arakawa, S.; Nagase, H.; Nakanishi, T.; Hu, J. Activation of peroxisome proliferatoractivated receptor gamma and disruption of progesterone synthesis of 2-ethylhexyl diphenyl phosphate in human placental choriocarcinoma cells: Comparison with triphenyl phosphate. Environ. Sci. Technol. 2017, 51 (7), 4061-4068.

(51) Li, F.; Xie, Q.; Li, X.; Li, N.; Chi, P.; Chen, J.; Wang, Z.; Hao, C. Hormone activity of hydroxylated polybrominated diphenyl ethers on human thyroid receptor: In vitro and in silico investigations. Environ. Health Perspect. 2010, 118 (5), 602-606.

(52) Li, F.; Wu, H.; Li, L.; Li, X.; Zhao, J.; Peijnenburg, W. J. G. M. Docking and QSAR study on the binding interactions between polycyclic aromatic hydrocarbons and estrogen receptor. Ecotoxicol. Environ. Saf. 2012, 80, 273-279.

(53) Genest, D.; Garnier, N.; Arrault, A.; Marot, C.; Morin-Allory, L.; Genest, M. Ligand-escape pathways from the ligand-binding domain of PPAR $\gamma$ receptor as probed by molecular dynamics simulations. Eur. Biophys. J. 2008, 37 (4), 369-379.

(54) Boelen, A.; Kwakkel, J.; Alkemade, A.; Renckens, R.; Kaptein, E.; Kuiper, G.; Wiersinga, W. M.; Visser, T. J. Induction of type 3 deiodinase activity in inflammatory cells of mice with chronic local inflammation. Endocrinology 2005, 146 (12), 5128-5134.

(55) Schweizer, U.; Schlicker, C.; Braun, D.; Köhrle, J.; Steegborn, C. Crystal structure of mammalian selenocysteine-dependent iodothyronine deiodinase suggests a peroxiredoxin-like catalytic mechanism. Proc. Natl. Acad. Sci. U. S. A. 2014, 111 (29), 1052610531.

(56) Gereben, B.; Zavacki, A. M.; Ribich, S.; Kim, B. W.; Huang, S. A.; Simonides, W. S.; Zeöld, A.; Bianco, A. C. Cellular and molecular basis of deiodinase-regulated thyroid hormone signaling. Endocr. Rev. 2008, 29 (7), 898-938.

(57) Wu, G. S.; Ding, Z. Caspase 9 is required for p53-dependent apoptosis and chemosensitivity in a human ovarian cancer cell line. Oncogene 2002, 21 (1), 1-8.

(58) Sun, Q.; Wang, R.; Wang, Y.; Luo, J.; Wang, P.; Cheng, B. Notch1 is a potential therapeutic target for the treatment of human hepatitis B virus X protein-associated hepatocellular carcinoma. Oncol. Rep. 2014, 31 (2), 933-939.

(59) Li, F.; Wang, L.; Ji, C.; Wu, H.; Zhao, J.; Tang, J. Toxicological effects of tris(2-chloropropyl) phosphate in human hepatic cells. Chemosphere 2017, 187, 88-96.

(60) Xiang, P.; Liu, R. Y.; Li, C.; Gao, P.; Cui, X. Y.; Ma, L. Q. Effects of organophosphorus flame retardant TDCPP on normal human corneal epithelial cells: Implications for human health. Environ. Pollut. 2017, 230, 22-30.

(61) UNEP. Global chemicals outlook II: From legacies to innovative solutions. https://www.unenvironment.org/resources/ report/global-chemicals-outlook-ii-legacies-innovative-solutions (accessed 23 October 2020).

(62) Judson, R.; Richard, A.; Dix, D. J.; Houck, K.; Martin, M.; Kavlock, R.; Dellarco, V.; Henry, T.; Holderman, T.; Sayre, P.; Tan, S.; Carpenter, T.; Smith, E. The toxicity data landscape for environmental chemicals. Environ. Health Perspect. 2009, 117 (5), 685-695.

(63) Jeong, J.; Choi, J. Adverse outcome pathways potentially related to hazard identification of microplastics based on toxicity mechanisms. Chemosphere 2019, 231, 249-255.

(64) Noyes, P. D.; Friedman, K. P.; Browne, P.; Haselman, J. T.; Gilbert, M. E.; Hornung, M. W.; Barone, S., Jr.; Crofton, K. M.; Laws, S. C.; Stoker, T. E.; Simmons, S. O.; Tietge, J. E.; Degitz, S. J. Evaluating chemicals for thyroid disruption: Opportunities and 
challenges with in vitro testing and adverse outcome pathway approaches. Environ. Health Perspect. 2019, 127 (9), 95001.

(65) OECD. The adverse outcome pathway for skin sensitisation initiated by covalent binding to proteins part 1: Scientific evidence: Health and safety publications series on testing and assessment. 2012. https://www.oecd.org/env/the-adverse-outcome-pathway-for-skinsensitisation-initiated-by-covalent-binding-to-proteins9789264221444-en.htm (accessed 18 September 2020).

(66) Guigueno, M. F.; Head, J. A.; Letcher, R. J.; Karouna-Renier, N.; Peters, L.; Hanas, A. M.; Fernie, K. J. Early life exposure to triphenyl phosphate: Effects on thyroid function, growth, and resting metabolic rate of Japanese quail (Coturnix japonica) chicks. Environ. Pollut. 2019, 253, 899-908.

(67) Honkakoski, P.; Palvimo, J. J.; Penttila, L.; Vepsalainen, J.; Auriola, S. Effects of triaryl phosphates on mouse and human nuclear receptors. Biochem. Pharmacol. 2004, 67 (1), 97-106.

(68) Ren, X. M.; Guo, L. H.; Gao, Y.; Zhang, B. T.; Wan, B. Hydroxylated polybrominated diphenyl ethers exhibit different activities on thyroid hormone receptors depending on their degree of bromination. Toxicol. Appl. Pharmacol. 2013, 268 (3), 256-63.

(69) Ren, X.; Cao, L.; Yang, Y.; Wan, B.; Wang, S.; Guo, L. In vitro assessment of thyroid hormone receptor activity of four organophosphate esters. J. Environ. Sci. 2016, 45, 185-90.

(70) Kojetin, D. J.; Matta-Camacho, E.; Hughes, T. S.; Srinivasan, S.; Nwachukwu, J. C.; Cavett, V.; Nowak, J.; Chalmers, M. J.; Marciano, D. P.; Kamenecka, T. M.; Shulman, A. I.; Rance, M.; Griffin, P. R.; Bruning, J. B.; Nettles, K. W. Structural mechanism for signal transduction in RXR nuclear receptor heterodimers. Nat. Commun. 2015, 6 (1), 8013.

(71) Li, X.; Sun, H.; Yao, Y.; Zhao, Z.; Qin, X.; Duan, Y.; Wang, L. Distribution of phthalate metabolites between paired maternal-fetal samples. Environ. Sci. Technol. 2018, 52 (11), 6626-6635.

(72) Wang, Q.; Shen, Y.; Ye, B.; Hu, H.; Fan, C.; Wang, T.; Zheng, Y.; Lv, J.; Ma, Y.; Xiang, M. Gene expression differences between thyroid carcinoma, thyroid adenoma and normal thyroid tissue. Oncol. Rep. 2018, 40 (6), 3359-3369.

(73) Bièche, I.; Franc, B.; Vidaud, D.; Vidaud, M.; Lidereau, R. Analyses of MYC, ERBB2, and CCND1 genes in benign and malignant thyroid follicular cell tumors by real-time polymerase chain reaction. Thyroid 2001, 11 (2), 147-152.

(74) Lai, E. C. Notch signaling: control of cell communication and cell fate. Development 2004, 131 (5), 965-973.

(75) Borggrefe, T.; Liefke, R. Fine-tuning of the intracellular canonical Notch signaling pathway. Cell Cycle 2012, 11 (2), 264-276.

(76) Verhein, K. C.; McCaw, Z.; Gladwell, W.; Trivedi, S.; Bushel, P. R.; Kleeberger, S. R. Novel roles for Notch3 and Notch4 receptors in gene expression and susceptibility to ozone-induced lung inflammation in mice. Environ. Health Perspect. 2015, 123 (8), 799-805.

(77) Purow, B. Notch inhibition as a promising new approach to cancer therapy. Adv. Exp. Med. Biol. 2012, 727, 305-319.

(78) Kumar, R.; Juillerat-Jeanneret, L.; Golshayan, D. Notch Antagonists: Potential Modulators of Cancer and Inflammatory Diseases. J. Med. Chem. 2016, 59 (17), 7719-7737.

(79) Yu, J.; Koenig, R. J. Regulation of hepatocyte thyroxine 5'deiodinase by T3 and nuclear receptor coactivators as a model of the sick euthyroid syndrome. J. Biol. Chem. 2000, 275 (49), 3829638301 .

(80) Liu, C.; Li, L.; Ha, M.; Qi, S.; Duan, P.; Yang, K. The PI3K/Akt and ERK pathways elevate thyroid hormone receptor $\beta 1$ and TRH receptor to decrease thyroid hormones after exposure to $\mathrm{PCB} 153$ and p,p'-DDE. Chemosphere 2015, 118, 229-238.

(81) Franke, T. F.; Hornik, C. P.; Segev, L.; Shostak, G. A.; Sugimoto, C. PI3K/Akt and apoptosis: size matters. Oncogene 2003, 22 (56), 8983-8998.

(82) Mebis, L.; Paletta, D.; Debaveye, Y.; Ellger, B.; Langouche, L.; D'Hoore, A.; Darras, V. M; Visser, T. J; Van den Berghe, G. Expression of thyroid hormone transporters during critical illness. Eur. J. Endocrinol. 2009, 161 (2), 243-250. 